\title{
A ConstruÇÃo dA EXPERIÊNCIA PERCEPTIVA: O QUE ISSO QUER DIZER?
}

\author{
GARY HATFIELD
}

\begin{abstract}
Classical constructivists such as Rock and Hoffman contend that the processes of perception are intelligent and construct perceptual experience by going beyond the stimulus information or by creating a percept that deviates from the physical properties of the object. On these terms, Gibson's theory of perception is anti-constructivist. After reviewing classical constructivism, this article maintains, first, that the phenomenology of visual space shows a deviation from physical spatial properties, by being contracted in depth, even under fullcue conditions, a fact that makes trouble for Gibson's version of direct realism. Second, independently of the first argument, it contends that perception is pervasively constructed in the sense that stimulus information must be transformed to yield perception. Accordingly, perception is radically constructed in its very bones.
\end{abstract}

Keywords: Construction in perception; visual space; Gestalt psychology; James J. Gibson; Donald D. Hoffman; radical constructivism.

\section{Introdução}

Afirmar que a experiência é construída pode significar muitas coisas. Uma concepção proeminente nesse assunto provém de Immanuel Kant, autor que desenvolveu uma elaborada análise a respeito de como os conceitos categoriais interagem com a percepção sensorial para construir a experiência de um mundo. Essa concepção denota um meio de produzir o mundo [way of world-making], muito antes de que Nelson Goodman (1978) tornasse essa expressão famosa. Ainda que Kant sustentasse que a percepção sensorial é crucial na construção da experiência, ele concedeu maior ênfase às categorias e à experiência de um mundo objetivo. Em contrapartida, este artigo focaliza a construção da experiência perceptiva básica, já que esta — daí a sua relevância - poderia ser não conceitual (apresentação de propriedades básicas como cor e forma, independentemente dos conceitos de cor e forma). O texto examina a construção na percepção espacial, especialmente na visão, concluindo que a construção está em toda parte. Esse resultado requer um construtivismo radical.

A ideia de que a experiência perceptiva é uma construção surge de duas fontes principais. Primeiramente, a crença no fato de que os sistemas perceptivos precisam manipular informação de modo inteligente para produzir percepção é considerada um indicador de que processos construtivos subjazem à percepção. Para a visão, isso significa que o sistema visual cria o mundo da experiência a partir de estímulos informacionais ambíguos. Em segundo lugar, o fato de que, às vezes (ou, possivelmente,

Principia 21(2): 167-188 (2017).

Published by NEL — Epistemology and Logic Research Group, Federal University of Santa Catarina (UFSC), Brazil. 
sempre), esta experiência perceptiva construída se afasta da realidade física é, por si mesmo, interpretado como um sinal de que a experiência é construída. O bem conhecido cubo de Necker ilustra ambos os pontos. Embora seja bidimensional, tendemos a experienciá-lo em três dimensões. Portanto, a terceira dimensão é acrescentada por meio de construção. Contudo, uma vez que a imagem no papel é plana e a experiência é tridimensional, a experiência se afasta da realidade física, sugerindo que a experiência inclui elementos construídos.

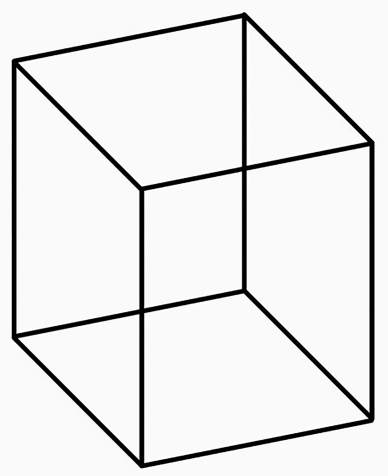

Figura 1. O cubo de Necker. O desenho é inicialmente percebido como um cubo espacial tendo como face frontal ou o quadrado contendo o canto superior esquerdo, ou o quadrado contendo o canto inferior direito. (Espere alguns momentos e o cubo percebido mudará). Com um pouco de prática, as linhas podem ser percebidas como um hexágono bidimensional, contendo triângulos, trapezoides e outras figuras internas.

Neste artigo, primeiramente, articulamos de modo mais completo essas concepções acerca da construção. Argumentamos, então, que a percepção espacial é profundamente construída, e que esta deve ser considerada dessa forma até mesmo por teóricos gibsonianos. Oferecemos uma noção de construção radical que não requer elaboração inferencial dos estímulos informacionais. Tal concepção pode se manter neutra a respeito dos mecanismos por meio dos quais a construção ocorre. A construção pode ser pervasiva, ainda que os processos perceptivos não sejam cognitivamente hábeis.

\section{Concepções da construção na percepção}

A primeira concepção sustenta que a percepção deve ser construída de modo inteligente a partir de informação empobrecida. Tal construção é geralmente compreendida como um processo cognitivo ou inferencial (ainda que o produto da percepção seja não conceitual). Uma motivação para invocar a construção é a noção de que a

Principia 21(2): 167-188 (2017). 
informação disponível para a percepção é reduzida ou inadequada. Para construir a percepção, um ato de reconstrução cognitiva é necessário, uma espécie de melhor suposição sobre o que está presente.

Nesse sentido, quando eu olho para uma cena, a base para minha percepção é composta por duas imagens empobrecidas na minha retina (talvez suplementadas por sensações oculomotoras). O psicólogo construtivista Irvin Rock (1982; 1983) propôs que os processos básicos que me permitem ver as formas, as dimensões e as cores das coisas envolvem a aplicação inteligente de regras a essa informação reduzida, de modo a produzir uma apresentação perceptiva do layout espacial e cromático. (Aqui, não consideramos o problema mais difícil de classificar e identificar os tipos de coisas e indivíduos na cena.) Rock concede que esta reconstrução possa ser boa o bastante, bem como completamente precisa ou verídica. Contudo, céticos apontam que, se a percepção é uma reconstrução a partir de informação pobre, ela está sujeita a erros e distorções da mesma maneira que outros processos reconstrutivos são falíveis e propensos ao erro. A memória, do modo como psicólogos a compreendem (por exemplo, Neisser e Libby 2000), é um desses processos reconstrutivos. No que se refere à visão, a ameaça é que a percepção construída seja uma mera fabricação ou invenção.

Essa primeira concepção é motivada pela discrepância entre a imagem bidimensional empobrecida na retina e a experiência perceptiva tridimensional, de modo que a construção compensa tal diferença. A segunda concepção principal opera em sentido inverso, pois parte da incompatibilidade entre a percepção e a cena física externa, concluindo, a partir daí, que a percepção é uma construção em sentido estrito. Donald Hoffman (1998) defende essa posição. Ele enfatiza as incompatibilidades tais como as descritas pelos princípios de organização da psicologia Gestalt. Tais incompatibilidades incluem relações entre figura e fundo, em que certas figuras se tornam mais salientes com respeito ao fundo, ainda que, fisicamente, elas possuam a mesma realidade enquanto superfícies - como é o caso nas relações entre as linhas pretas e a superfície branca do desenho do cubo de Necker. Essas incompatibilidades também incluem casos em que a mesma forma física assume diferentes organizações na ausência de qualquer mudança intrínseca, tal como ocorre quando o cubo muda de orientação (uma "mudança de Gestalt"). A mudança percebida quanto à orientação do cubo é um acréscimo subjetivo sem qualquer realidade física correspondente, o que produz duas percepções tridimensionais errôneas a partir do mesmo grupo de linhas pretas bidimensionais. Hoffman conclui que, uma vez que a percepção é construída nesse tipo de caso, ela poderia ser irrestrita e meramente uma construção, isto é, uma fabricação ou invenção (1998, cap.8).

Tradicionalmente, a posição oposta ao construtivismo em psicologia da percepção é o realismo direto gibsoniano. James J. Gibson (1950; 1966; 1979) argumentou que informação abundante se encontra disponível aos sistemas visuais quando se ve- 
rificam condições ordinárias de visão - um observador móvel com ambos os olhos abertos e boa iluminação. Essa informação é suficiente para especificar o layout espacial. Não há necessidade de processos reconstrutivos "inteligentes" ou "hábeis". Nós percebemos o mundo veridicamente por meio da simples captação de informação abundante. (Acerca da controvérsia entre a teoria gibsoniana e o construtivismo, ver Norman 2001.)

Um contraponto filosófico ao realismo direto de Gibson é o realismo direto ingênuo, atualmente em alta em partes da Inglaterra, da Califórnia e de Nova Jersey. Nessa visão, nenhuma construção é necessária, pois o mundo, com suas propriedades físicas, é diretamente acessível à mente consciente por meio de uma relação de apreensão [acquaintance] não mediada. Detalhei as lacunas dessa forma de teoria não construtivista em outro texto (Hatfield 2016). Assim, deixarei de lado essa teoria para que nos concentremos nas ideias de Rock, Hoffman, Gibson e, conforme for o caso, dos psicólogos da Gestalt, especialmente Kurt Koffka (1935).

Recapitulando, os dois primeiros autores sustentam que a percepção é uma construção, mas discordam quanto a determinar se isso compromete a possibilidade de que a percepção seja verídica. Rock (1981, p.502; 1983, p.302) mantém a questão aberta, sustentando que as construções perceptivas podem (ou não) ser verídicas. Hoffman (1998) defende que a percepção é suspeita, visto que consiste numa construção que se afasta da realidade física, assim como nos efeitos de Gestalt. É possível que a percepção seja uma reconstrução profundamente falha daquilo que realmente há. Por sua vez, Gibson $(1966 ; 1979)$ argumenta que, em virtude da informação visual - quando corretamente analisada - ser capaz de especificar as propriedades físicas da cena, não há necessidade de construção; geralmente, a percepção nos apresenta veridicamente as propriedades físicas de uma realidade independente da mente.

Hoffman e Gibson concordam que qualquer afastamento da experiência fenomênica com relação ao ambiente físico externo conta como evidência de construção (ainda que Gibson sustente que tal afastamento seja aberrante). Podemos denominar essa concepção comum de construção como AFA:

AFA (Afastamento Fenomênico do Ambiente Físico): ${ }^{1} \mathrm{O}$ afastamento da experiência fenomênica em relação ao ambiente físico externo indica construção perceptiva.

Os psicólogos da Gestalt, a quem recorrem Hoffman e Gibson, concordam em princípio com AFA, mas sem utilizar a terminologia de "construção". Isto é, eles reconhecem que o ambiente comportamental experienciado se afasta do ambiente físico ou geográfico devido a processos perceptivos (Koffka 1935, pp.27-41). Tanto Hoffman quanto Gibson consideram esse afastamento como um tipo de percepção errônea. Com relação a esse ponto, eu discordo, assim como discordariam os gestaltistas.

Principia 21(2): 167-188 (2017). 
Já que discordo, gostaria de traçar um mapa diferente das relações entre essas posições, bem como das implicações que seguem da aceitação da tese de que a percepção é construtiva. Para isso, preciso, primeiramente, ampliar a noção de construção. Quero incluir todos os casos em que o sistema visual precisa transformar seu input a fim de produzir percepção. Portanto, endosso o princípio CT:

CT (Construção como Transformação): ${ }^{2}$ Qualquer aspecto da percepção que seja diferente do estímulo proximal como este é recebido pelos órgãos dos sentidos deve ser considerado uma transformação e, portanto, uma construção.

CT amplia a noção de construção, que passa a incluir como transformação e, portanto, construção - todas as instâncias em que aquilo que é percebido difere regularmente das distribuições de energia recebidas pelos órgãos dos sentidos. Rock já concorda. Os gestaltistas (Koffka 1935, pp.129-41; Köhler 1947, pp.132-3) reconhecem com satisfação que os processos perceptivos na visão respondem ao mosaico de estímulos bidimensionais produzindo uma experiência em três dimensões. Esta apresenta o mundo de acordo com um aspecto específico (incluindo características organizacionais tais como a relação entre figura e pano de fundo). Gibson poderia afirmar que não está comprometido com qualquer tipo de construção perceptiva, exceto em casos desviantes.

CT pode parecer tão amplo a ponto de se tornar fraco. Minha tarefa é mostrar que, de fato, sob essa noção ampla, são reveladas instâncias de construção impressionantes - mas frequentemente despercebidas. Mostrarei que tais transformações e construções precisam ocorrer até mesmo na teoria de Gibson. Com efeito, é apenas a partir da perspectiva implausível do realismo ingênuo que a percepção se limita a copiar, ou diretamente englobar, objetos físicos. Qualquer descrição dos processos perceptivos que conceda atenção suficiente às características da estimulação óptica notará que aquilo que os olhos recebem - por mais abundante que seja do ponto de vista informativo — não é uma cópia do mundo e, portanto, precisa ser transformado para produzir percepção.

Argumentarei ainda que os desvios perceptivos na apresentação de propriedades físicas externas não precisam ser caracterizados como casos de percepção errônea, nem mesmo como percepções não verídicas. Nesses casos, os padrões que fixam o que é verídico situam as apresentações do ambiente de um modo adequado para orientar a ação:

AA (Aspecto para Ação): ${ }^{3}$ A percepção apresenta o ambiente sob certo aspecto e de certa maneira apropriada para orientar a ação; desvios com relação às propriedades independentes da mente não precisam ser consideradas como um "erro".

Oferecerei bases fenomênicas para crer que a percepção espacial ordinária não corresponde à cena física, mas a apresenta sob determinado aspecto. Seguindo os 
psicólogos da Gestalt por um momento, há uma diferença entre um ambiente comportamental descrito fenomenicamente e o ambiente geográfico ou físico que a experiência fenomênica apresenta (Koffka 1935, pp.27-31). O ambiente comportamental, embora não seja uma cópia literal do ambiente físico, apresenta, não obstante, este ambiente de um modo confiável para que se possa agir nele.

Consequentemente, a percepção é mais profundamente construída do que consideram as noções construtivistas usuais. A percepção inclui uma construção fenomênica que difere da mera representação da realidade independente da mente, e isto não precisa ser considerado algo negativo. Com efeito, para o propósito da orientação da ação, uma construção fenomênica dependente do sujeito e situada no ambiente pode ser, talvez, a única coisa necessária.

\section{Construtivismo, Gibson, e Gestalt acerca da experiência fenomênica}

Gibson (1966, cap.10, 11, 14; 1979, cap.14) considerava que a teoria aceita sobre a percepção visual - a concepção construtivista tradicional — consiste nos seguintes pontos centrais: o estímulo para visão espacial é empobrecido, sendo incapaz de especificar a terceira dimensão; este estímulo produz "sensações" que espelham o estímulo proximal (a imagem da retina, no caso da visão); a fim de compensar, são necessários cálculos ou inferências baseadas na memória ou na experiência passada, sendo que estes produzem uma percepção construída que pode ser ou não ser verídica.

A concepção construtivista pode ser ilustrada levando em consideração os seguintes diagramas da hipótese de invariância tamanho-distância (HITD). ${ }^{4}$ A Figura 2 exibe a relação física entre a altura de objetos, a distância entre eles e o seu ângulo visual (que se correlaciona diretamente com suas projeções na retina). Objetos de mesma altura, situados a diferentes distâncias, produzem projeções na retina que diminuem à medida que a distância do objeto aumenta (Fig. 2a). Um objeto de altura elevada (Fig. 2b, $A$ ) e outro menor $(C)$ podem produzir o mesmo ângulo visual (projeção na retina). Mas como eles são percebidos? Rock sustentava que a percepção, ao menos para objetos próximos, atinge frequentemente constância fenomênica completa com respeito ao tamanho (1975, pp.31-2; 1982, p.528, p.532). O tamanho percebido (neste caso, a altura) depende tanto do ângulo visual (constante para certo objeto situado a determinada distância física) quanto da distância percebida. Se a distância é percebida de modo preciso, então os objetos são percebidos nas suas localizações verdadeiras e com seus tamanhos verdadeiros ( $A$ e $C$ ), um resultado conhecido como constância com relação ao tamanho. Se a distância é percebida como sendo menor ou maior, então os objetos são vistos como mais próximos ou meno-

Principia 21(2): 167-188 (2017). 
res (em $B$ e $E$ ) ou como mais distantes ou maiores ( $A$ percebido como $D$ ), o que chamamos respectivamente subconstância ou sobreconstância.

(a)

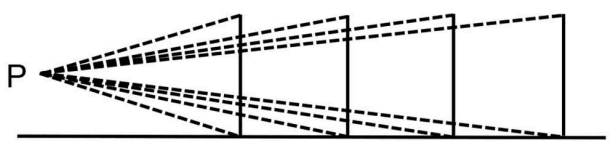

(b)

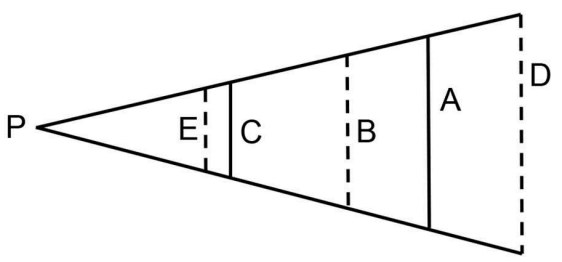

Figura 2. A parte (a) mostra postes de altura igual em diferentes distâncias. Os postes mais distantes produzem ângulos visuais (imagens retinais) menores. Se a distância percebida corresponde à distância física, então, de acordo com a HITD, o tamanho percebido corresponde ao tamanho físico. A parte (b) ilustra a HITD para dois objetos, A e C, que estão em distâncias diferentes, mas projetam o mesmo ângulo visual. Dependendo da distância percebida dos objetos, o tamanho percebido varia.

Para substituir a perspectiva construtivista, Gibson propôs que o estímulo para a visão traz informação abundante que especifica inequivocamente o layout espacial. Essa informação é tomada pelo sistema visual para produzir uma percepção direta do layout com suas propriedades objetivas, (supostamente) evitando a necessidade de computações ou inferências. Na percepção verídica normal, nós não possuímos experiências perceptivas mediadoras, nem de uma "sensação" proximal nem de uma cena visual objetiva. Sob condições empobrecidas de estímulo, a constância com relação ao tamanho e a forma pode se desmembrar, revelando, de acordo com o construtivismo, os verdadeiros elementos da percepção: objetos mais distantes produzem sensações referentes a tamanhos menores, moedas vistas sob certa inclinação produzem sensações referentes à forma elíptica. Entretanto, de acordo com Gibson, longe de serem fundamentais, essas sensações aberrantes não desempenham qualquer papel na situação ecologicamente normal de estimulação abundante, na qual a cena é percebida tal como ela é (1966, caps.10, 12; 1979, caps.4, 14).

Principia 21(2): 167-188 (2017). 
Com frequência, Gibson deu a entender que as únicas opções disponíveis são sensações proximais empobrecidas ou percepção direta do layout físico (1950, cap.3; 1966, cap.14). Ele defendeu que, ao considerar as coisas que parecem menores quando situadas a certa distância ou a moeda que parece elíptica sob certa inclinação, estamos assimilando, de modo forçado, as sensações proximais à experiência. Isso se dá ou por meio de condições pobres de visão ou por meio da adoção de determinada atitude especial, denominada atitude pictórica, que produz uma experiência correspondente à projeção em perspectiva de uma cena num plano bidimensional (1950, p.27; 1966, pp.235-8, pp.306-7). Sem as condições empobrecidas ou atitude pictórica, as coisas não deveriam parecer pequenas quando situadas a certa distância, se tivermos informações completas e condições ótimas de visualização. De fato, Gibson reconheceu que, caso a percepção sob condições ótimas não se conforme aos "fatos objetivos" (1966, p.6, p.306) do ambiente, sua teoria estaria em apuros (1966, p.306; 1979, pp.166-7). Exemplos problemáticos incluiriam "constância perceptiva incompleta" (1966, p.306; 1979, p.160), como quando uma moeda parece elíptica ou os trilhos de uma ferrovia convergem fenomenicamente.

Supondo que constância incompleta fosse encontrada em casos de percepção sob condições ótimas, Gibson defendeu que ou esse tipo de resultado descrito reflete uma fenomenologia ruim, ou que a adoção da atitude pictórica cria sensações que invadem a experiência. Ele se contrapôs à hipótese de fenomenologia ruim afirmando que a moeda se parece com um círculo sob inclinação de modo que, exceto quando vista a partir de um ângulo extremo, ela se parece com um círculo. Essa resposta me parece atraente. $\mathrm{O}$ autor respondeu à alegação de que as coisas parecem pequenas a certa distância afirmando que, na verdade, elas não parecem. Ele citou um experimento envolvendo estacas numa paisagem aberta em que foram obtidas respostas médias de constância completa até mesmo a uma distância de 700 metros (1950, pp. 174-87; 1979, p. 160). Se isso significa que, sob condições perceptivas ordinárias, não há diminuição fenomênica a distâncias de 200 metros — ou 30 ou 7 metros — permaneço cético. Não acredito nisso. Não estou dizendo que, para um observador adulto, as coisas a distância se parecem como se estivessem fisicamente menores. Nem mesmo estou negando que se possa alterar a experiência de tamanho por meio da adoção da atitude pictórica. Porém, estou afirmando que, na percepção normal, sem a atitude pictórica, as coisas são fenomenicamente diminuídas a distância (tal como concede Rock 1982, p.533).

Retornemos ao ponto fenomenológico. Gibson considerava a tradição da Gestalt como distinta do construtivismo padrão (1950, pp.22-3; 1966, pp.266-7). Os Principles of Gestalt Psychology de Koffka apresentam uma teoria da percepção que aceita o empobrecimento do estímulo com relação à experiência perceptiva, mas que rejeita a ideia de que a experiência perceptiva resulta de operações inteligentes baseadas em sensações proximais (1935, pp.85-8). O estímulo empobrecido é capaz de produ- 
zir uma apresentação de um mundo espacial e cromático, uma vez que os processos cerebrais operam dinamicamente para produzir percepção organizada, tendendo na direção das constâncias com relação à forma, ao tamanho e à cor. Essa organização inclui relações entre figura e pano de fundo (incluindo contraste aumentado nas bordas), agrupamentos por proximidade e similaridade, uma tendência em direção à simetria e à simplicidade, e assim por diante. (Sobre as relações entre Gibson, os psicólogos da Gestalt e o construtivismo de Rock, ver Epstein 1994.)

Os psicólogos da Gestalt aceitam a distinção entre objetos físicos e a experiência perceptiva acerca desses objetos. Os objetos físicos não são diretamente apresentados à consciência, mas nossa experiência perceptiva faz a "mediação" do contato com o ambiente físico. Koffka denominava o mundo da experiência imediata como o ambiente comportamental, em oposição ao ambiente geográfico ou físico. Num exemplo famoso, um cavaleiro na região do Lago Constança, na fronteira entre Alemanha, Áustria e Suíça, cavalga sobre terra firme no seu ambiente comportamental (ele percebe a extensão plana do lago coberta por neve como uma campina nevada), mas no seu ambiente geográfico ele cavalga, de fato, sobre a fina camada de gelo sobre o lago, que sustenta o seu peso (1935, pp.27-8). Koffka descreve o ambiente comportamental fenomenicamente presente como atingindo "a mediação entre o ambiente geográfico e o comportamento" (1935, p.36).

Ainda que seja possível interpretar esse ambiente comportamental como um tipo de dado dos sentidos, não leio Koffka dessa maneira. Em vez disso, o ambiente comportamental é uma apresentação do ambiente geográfico sob determinado aspecto. Ele apresenta o mundo fenomenicamente, de uma maneira subjetivamente condicionada. Além disso, os gestaltistas não acreditam na tese de que a percepção, a fim de ser correta, deve apresentar apenas estruturas físicas objetivas e independentes da mente. A percepção apresenta o mundo como possuindo uma organização entre figura e pano de fundo, bordas realçadas, agrupamentos, e assim por diante. Os defensores da Gestalt não consideram esses afastamentos de uma descrição física neutra como ilusórios ou errôneos. Como ilustrado pela fotografia a seguir (Fig. 3), a organização entre figura e pano de fundo pode realçar os limites dos objetos, bem como separar estruturas sobrepostas no espaço.

Acredito que Gibson considerou esses afastamentos em relação à física como erros. Sua psicologia ecológica levou em conta fatos "ecológicos" tais como a escala do ambiente em relação ao organismo, a colocação do organismo em relação a uma cena, condições usuais de iluminação e de superfícies e a relação do animal com o meio, como o ar, a terra ou a água. Ele disse que esses fatores apresentam um elemento "subjetivo", e com isso ele não queria dizer um aspecto dependente da mente, mas a relação física do sujeito com a cena, incluindo o tamanho físico do sujeito em relação ao tamanho físico das coisas. Ele manteve a noção de que "objetivo" significa o que é determinado por propriedades físicas ordinárias (1966, p.6, p.306; 1979, 


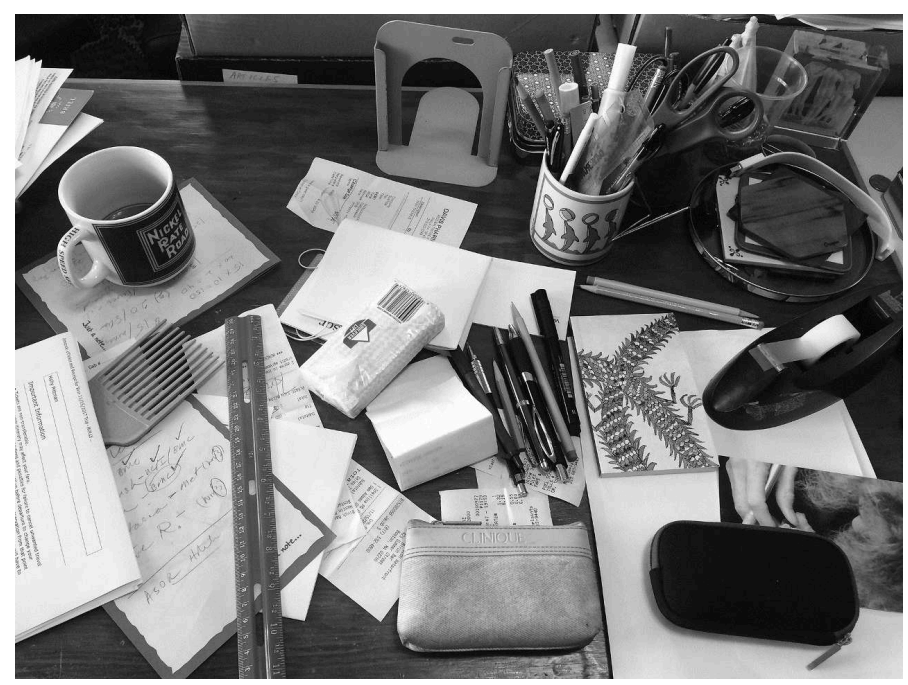

Figura 3. A organização entre figura e pano de fundo segrega os diversos itens como unidades fenomênicas, incluindo a apresentação de superfícies como contínuas sob unidades menores e a segregação de diversas unidades menores umas das outras.

pp.8-9, p.126, p.129, cap. 9). E, portanto, ele não escapou, como poderia ter feito, da predileção dos realistas ingênuos por um mundo físico "objetivo" que é revelado pela percepção (embora numa escala organísmica).

Agora podemos retornar à percepção de tamanho e à fenomenologia das coisas que parecem pequenas a distância. Lembre que Gibson acreditava que essa fenomenologia é produzida artificialmente, pela adoção de uma atitude pictórica, de modo a experienciar uma imagem em perspectiva bidimensional da cena. Nossa atitude produz uma experiência de tamanhos e formatos intermediários (como numa representação pictórica em perspectiva). Porém, ele afirma, com informação completa e sem adotar uma atitude, deveríamos perceber formas como são e no lugar onde estão com seus tamanhos verdadeiros. Ele sustentou que, no caso normal, há informação para especificar os tamanhos verdadeiros das coisas. Exemplos incluem o fato de que um objeto sobre o pano de fundo cobre a mesma quantidade de textura (homogênea) de pano de fundo independentemente da distância. Essa relação invariante entre textura de pano de fundo e tamanho oferece a informação para constância de tamanho (Gibson 1979, p.163). Ou então, para uma pessoa que está em pé olhando uma fileira de postes de iluminação, todos com a mesma altura, é possível notar que tanto os postes próximos quanto os postes distantes são cortados pela linha do horizonte no mesmo lugar proporcional; dado que a altura do olho é conhecida, a informação para as alturas físicas dos postes está presente por meio das relações proporcionais (Gibson 1979, p.165). Gibson afirmou que essas razões de ordem mais 
elevada no arranjo de estímulos especificam o layout "objetivo", isto é, físico (1979, p.126, p.129, cap.9), evitando, dessa forma, qualquer necessidade de representações subjetivamente condicionadas.

Há pontos que devem ser conceitualmente desafiados na abordagem de Gibson. Por exemplo, é possível se perguntar por que a recepção, no sistema visual, de informação suficiente para especificar o layout deveria produzir uma apreensão [acquaintance] imediata direta de objetos, como postulado (problematicamente) pelo realismo direto ingênuo. Mas eu prefiro montar um desafio fenomenológico. Acredito que Gibson incorreu em um falso dilema quando atribuiu às sensações intrusas a fenomenologia de constância intermediária. Ao contrário do que ele supôs, a reflexão fenomenológica, também amparada por evidência experimental, sugere que resultados intermediários são bastante normais.

Consideremos a noção de constância de tamanho e as coisas que parecem menores a distância. Koffka (1935, p.229) sustentou que a hipótese da invariância tamanhodistância dá conta deste caso. A HITD por si só não especifica que tamanho algo parecerá ter, mas diz que, mantendo constante o ângulo visual, o tamanho percebido de um objeto varia com sua distância percebida (Fig. 2b). Se um objeto é percebido como estando à sua distância física verdadeira, então ele deve ser percebido com o seu tamanho verdadeiro; se é percebido como mais próximo, então será fenomenicamente menor.

A percepção de trilhos de uma ferrovia que se prolongam na distância, ou de um longo corredor reto oferece contraexemplos à fenomenologia de Gibson. Eu percebo trilhos de trem como convergindo (Fig. 4). Essa convergência não é, como supõe Gibson, meramente uma convergência em perspectiva. Se assim fosse, eu teria a experiência dos trilhos como em uma projeção de perspectiva bidimensional, o que significaria - para o plano de perspectiva usual perpendicular à linha de visão que os trilhos pareceriam perpendiculares ao chão e se projetariam em um triângulo vertical truncado (Fig. 4, à direita). Mas minha experiência, ao olhar para os trilhos, é de vê-los sumindo à distância (na terceira dimensão). Eles convergem, mas só fazem isso à medida que se prolongam em direção ao horizonte. E, com efeito, existe boa evidência de que, na percepção normal, a distância percebida é insuficiente para estimar a distância física - mais ainda quando as coisas estão mais longe (Hillebrand 1902; Blumenfeld 1903; Wagner 2006, caps.6-7; veja também Hatfield 2003; 2016).

Para entender a regularidade dessa fenomenologia, considere a Figura 5, que é um desenho de Aage Slomann (1968). O desenho mostra um espaço retangular, digamos, um corredor, com um piso fisicamente plano $\mathrm{Ff}$ que vai dos pés do observador $P_{1}$ (em $d$ ) até o bastão $b c$. Slomann relata que não temos a experiência do piso como "plano" no sentido de formar um ângulo de noventa graus com o corpo do observador (ou de ser perpendicular à gravidade), mas que o piso fenomenicamente sobe. Eu concordo. E se o piso sobe enquanto as direções para lugares no piso físico permane- 

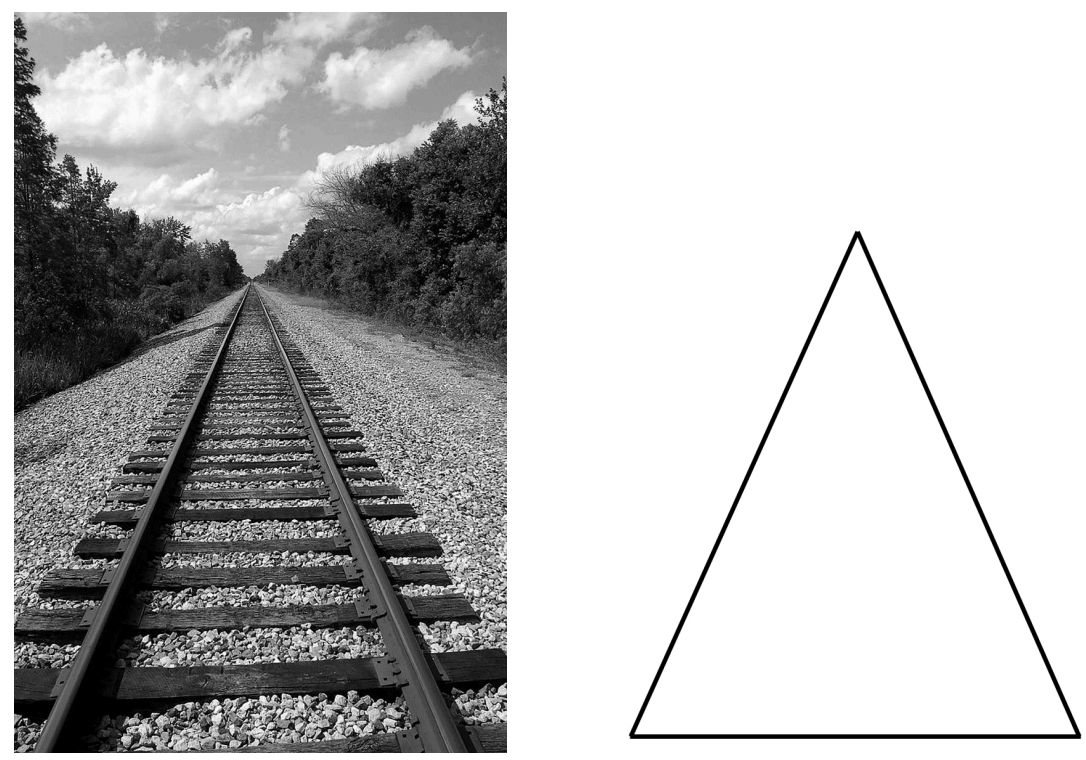

Figura 4. Trilhos ferroviários percebidos como convergindo à distância. A fotografia (à esquerda) dá uma sensação de profundidade; em uma ferrovia real, a sensação de profundidade e distância é ainda mais saliente. Se nossa experiência correspondesse a uma projeção perspectiva, ela seria um triângulo vertical (à direita).

cem as mesmas (isto é, enquanto continuamos percebendo direções veridicamente, o que de fato fazemos), então a distância deve estar sendo sub-percebida. Por exemplo, o local c aparece na direção dada pela linha $a c$, mas, porque é visto em relação ao piso, esse local aparece em $f$, na distância menor af . Tomando essa condição do chão fenomenicamente subindo como algo geral, então, de acordo com a HITD, objetos a certa distância parecerão mais próximos e menores, da maneira como o bastão físico $b c$ aparece na localização fenomênica $g f$. O espaço se contrai na dimensão da profundidade (ao longo das linhas de visão). Não há, de fato, qualquer razão óptica pela qual o chão não pudesse parecer plano e as coisas aparecessem onde elas estão e em seus tamanhos verdadeiros (por exemplo, o bastão $b c$ no local $b c$ ). Porém, isso seria bastante estranho para nós: significaria que os trilhos de trem não parecem convergir ou que prédios a um quilômetro de distância não são fenomenicamente de menor extensão do que os mesmos prédios a 20 metros.

É preciso repetir que essa diminuição ou contração, apesar de relacionada à perspectiva, não é a mesma coisa que a perspectiva linear, que é a projeção do mundo tridimensional em um plano bidimensional. O espaço contraído pode ser visto como uma apresentação fenomênica do ambiente geográfico ou físico sob um aspecto em que a distância contrai de maneira regular. Neste espaço visual, muita informação útil 


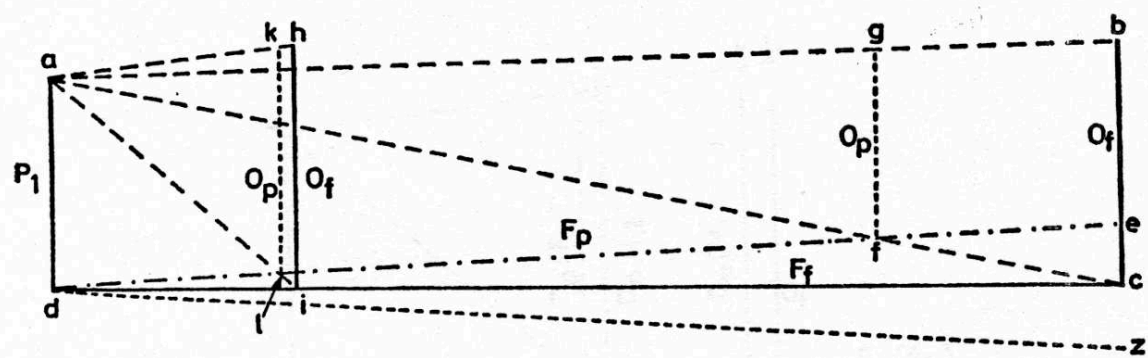

Figura 5. Uma ilustração dos efeitos sobre o espaço visual fenomênico se a distância é subpercebida. Para o observador $P_{1}(a d)$, o chão $(d c)$ parece subir $(d e)$ e os objetos parecem mais próximos e menores ( $b c$ aparece em $g f$ ). Fonte: Slomann (1968, Fig.1)

está fenomenicamente disponível: a direção fenomênica é congruente com a direção física, os objetos mantêm uma proporção invariante com seus arredores através de diferentes distâncias e tamanhos fenomênicos, relações de proximidade sobre superfícies são preservadas, assim como relações ordinais ao longo do plano do chão, e assim por diante (veja Hatfield 2012; 2016). Experiências fenomênicas dessas relações satisfazem uma norma para a percepção em conformidade com AA, de que a percepção apresenta o ambiente sob um aspecto adequado para orientar a ação. Tais normas incluem aparecer na direção certa, manter tamanho proporcional, e assim por diante. Desvios de propriedades físicas independentes do observador não precisam ser um "erro". Com efeito, é presumivelmente melhor que as coisas que estão a 100m de distância não pareçam ter o mesmo tamanho fenomênico que têm quando estão ao alcance da mão.

Essas descobertas contestam a fenomenologia de Gibson. Constância de tamanho é intermediária (veja também Daoust 2017). O formato, na escala de um corredor, também é afetado (o chão de um longo corredor retangular aparece como um trapezoide alongado). Como Gibson percebeu, isso favorece a mediação fenomênica. Se o objeto não está diretamente presente na experiência, mas é apresentado de maneira subjetivamente condicionada, então o lugar natural para encontrá-lo como apresentado sob um aspecto é na experiência fenomênica subjetivamente condicionada. Os gestaltistas e Gibson concordam a respeito disso (mesmo que Gibson tente evitar a conclusão por meio de seu argumento fenomenológico). Eles aceitam uma lógica antiquíssima para traçar uma distinção entre aparência e realidade: que propriedades como presentes na experiência desviam de propriedades físicas independentes da mente. Isso não exige, por sinal, compromisso com as aparências como dados dos sentidos. As aparências podem ser concebidas como apresentando o mundo físico sob um aspecto (Hatfield 2016).

De maneira oposta ao realismo direto de Gibson, não percebemos o mundo sim-

Principia 21(2): 167-188 (2017). 
plesmente como ele é fisicamente. Isso levanta a seguinte questão sobre tamanho: mesmo que Gibson esteja correto ao afirmar que, em situações ecologicamente normais, há informação suficiente para especificar distância e tamanho físicos, por que o valor físico seria o alvo da percepção? O que há de errado com o espaço contraído, se é ecologicamente adequado, e talvez preferível, para orientar a ação? A percepção de tamanho pode dizer respeito a relações, direções e proporções, apresentadas perceptualmente de modo a orientar a ação. Ela não precisa ser a respeito de tamanhos e distâncias independentes da mente, embora estas possam ser determinadas a partir do layout como percebidas, por meio de operações conhecidas de medição ou estimativa.

Se aceitarmos a intermediação fenomênica da percepção de tamanho, então devemos aceitar que a percepção é uma construção, em conformidade com AFA (afastamento fenomênico do ambiente físico):

AFA: O afastamento da experiência fenomênica em relação ao ambiente físico externo indica construção perceptiva.

Os gestaltistas podem assumir esse ponto e vê-lo como uma extensão de sua noção de que processos perceptivos produzem organização fenomênica que é benéfica. Rock e Hoffman já aceitaram essa conclusão. Gibson não aceitaria o afastamento fenomênico em casos normais, mas isso é problema dele. E, na verdade, um problema maior ainda está por vir.

\section{Percepção como radicalmente construída}

Consideremos agora a percepção como construída em conformidade com CT, construção como transformação:

CT: Qualquer aspecto da percepção que seja diferente do estímulo proximal como este é recebido pelos órgãos dos sentidos deve ser considerado uma transformação e, portanto, uma construção.

Há exemplos óbvios de tais transformações, como na concepção de Rock de que informações ambíguas de estímulo bidimensional devem ser transformadas por processos perceptivos inteligentes para produzir a experiência de superfícies em três dimensões. Hoffman concederia que a construção na percepção envolve, de alguma forma, a transformação do que está contido nas imagens da retina em perceptos organizados. Os gestaltistas aceitariam algo similar - embora, claro, sem conceber, com Rock e Hoffman, que os processos são cognitivamente hábeis ou inteligentes. Gibson concederia que tal transformação ocorre no caso de ilusões. Se fosse de outra forma, ele não aceitaria que ocorre construção na percepção cotidiana em condições ótimas de um mundo tridimensional. Minha primeira tarefa é mostrar que mesmo

Principia 21(2): 167-188 (2017). 
deixando de lado o critério fenomênico para a construção da seção anterior (AFA), isto é, colocando de lado por enquanto o meu argumento fenomenológico, Gibson e seus seguidores deveriam aceitar esta noção mais ampla de construção na percepção.

Vamos continuar admitindo as afirmações gibsonianas sobre informação abundante. Ainda assim, precisa-se de um mecanismo ou processo para transformar informação de estímulo em percepção do mundo visual. A informação disponível para o sistema visual não copia o mundo. Ao invés disso, ela o especifica em relação a um sistema que está em sintonia, e entra em ressonância, com a informação disponível.

Um exemplo pode ajudar. Os gibsonianos analisaram com sucesso padrões de fluxo óptico que produzem a percepção do movimento do observador através do ambiente (veja Warren 2008). Quando um observador se move para a frente em um ambiente estático com textura óptica normal, esse movimento produz um padrão de fluxo de expansão radial para fora em cada olho (Fig. 6). Essa informação resulta em uma experiência de movimento para a frente através do ambiente. Há, entretanto, uma diferença óbvia entre expansão no arranjo óptico - a qual pode ser representada em duas dimensões, como numa amostra da superfície bidimensional da retina - e a experiência fenomênica visual de se mover para a frente em profundidade. Gibson reconheceu essa diferença e apresentou uma divisão de trabalho para lidar com ela. Como um psicólogo, ele estava trabalhando no âmbito de sistemas perceptivos e da análise de variáveis de estímulo. Se ele encontrasse uma relação psicofísica entre expansão óptica e percepção de movimento para a frente, ele dizia, então, que o sistema perceptivo detecta a informação que especifica o movimento. Se pressionado a explicar como isso ocorre, ele concedia que receptores respondem a baixa energia, mas mantinha que não era trabalho dele dizer como os receptores e o sistema nervoso visual integram os padrões de estímulo. Ele estava pronto para seguir adiante depois de encontrar informações complexas de estímulo que especificam o ambiente físico (1950, p.viii; 1966, pp.2-5, p.167; 1979, p.53, p.251, p.263).

Mesmo assim, Gibson concedeu que neurocientistas podem perguntar como sistemas receptores respondem e integram as informações no fluxo óptico (1979, p.251). Os neurocientistas responderam ao procurar mecanismos neurais para detectar o fluxo óptico. Um dos primeiros esforços foi feito por van de Grind (1988). Ele propôs mecanismos neurais de detecção de movimento organizados em um anel (veja também Duffy 2004). Para um fluxo óptico global, os detectores estariam arranjados em anéis concêntricos em torno da fóvea. Os detectores de movimento são específicos para velocidade e direção. Esses detectores seriam orientados de modo a responder ao movimento local de características que se movem para fora em linhas radiais e cruzando os anéis concêntricos perpendicularmente. Van de Grind sugeriu um mecanismo similar para expansões ópticas mais localizadas com a informação de que um objeto, como uma bola de futebol, está se aproximando da cabeça do observador. Esses dois mecanismos tomam como input a expansão óptica global ou local e pro- 


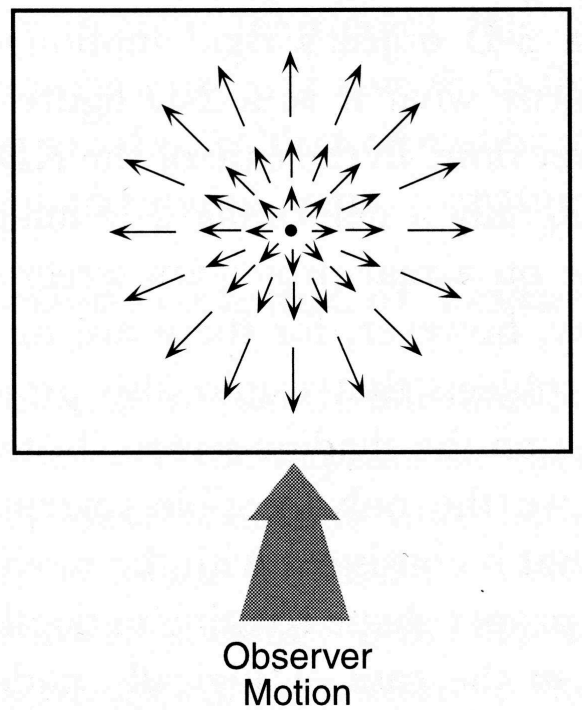

Figura 6. Um padrão de fluxo óptico produzido pelo movimento para a frente de um observador através de um meio estacionário com textura óptica normal. Características ópticas expandem a partir do ponto de fixação na cena. Fonte: Palmer (1999, p. 227).

duzem a experiência perceptiva ou de um objeto que se amplia vindo na direção do observador, ou do observador se movendo para a frente. Por CT, essas são instâncias de construção como transformação.

Um gibsoniano poderia apresentar a objeção de que não há construção porque não precisa haver processos subjacentes "inteligentes" ou hiperintelectualizados. Mas note que eu não caracterizei os processos como simbólicos, conceituais, inferenciais, ou nada parecido com o leque usual de palavras associadas à construção rockiana. Isso é porque eu procurei representar o critério para construção de maneira neutra entre Rock e Gibson. O ponto é definir construção, como quer que seja concebida, como um processo perceptivo em que a percepção resulta de uma transformação de valores de estímulo. Claramente temos uma transformação no caso dos padrões de fluxo óptico, os quais não são tridimensionais, mas produzem a percepção de movimento em três dimensões (movimento do observador ou movimento da bola). Esse tipo de construção é necessário mesmo se aceitarmos a informação abundante de Gibson. Em conformidade com a neutralidade, quaisquer "computações" envolvidas podem ser efetuadas por redes conexionistas não conceituais ou por inferências inteligentes rockianas (veja Hatfield 1990). CT não especifica. Consequentemente, o construtivismo cognitivo, como o de Rock ou o de Hoffman, torna-se uma subespécie de construção como transformação (CT).

Principia 21(2): 167-188 (2017). 
Contudo, agora eu quero convencer você de que a percepção é ainda mais radicalmente construída - que ela é construída até nos ossos. Comecemos com um aspecto bastante básico da visão: que nós vemos em linhas retas. Isso foi teorizado desde os tempos antigos e medievais, nos escritos sobre óptica de Euclides, Ptolomeu, Alhazen e Vitello (veja Lindberg 1976). A geometria precisa pela qual a luz alcança a retina foi descoberta por Kepler e ilustrada por Descartes em seus amplamente conhecidos escritos sobre óptica e fisiologia visual, a Dióptrica (1637) e o Tratado do Homem (1664). Esta descoberta é ilustrada aqui na Figura 7, que traz o diagrama de Descartes, de 1637. O caminho físico da luz é mostrado desde os pontos iluminados $V, X$ e $Y$ até os lugares na retina $R, S$ e $T$. Note que os feixes de luz vêm de cada ponto (ou pequena área) no objeto $V Y$. Esses feixes banham toda a frente do olho, mas, devido ao poder de refração da córnea (a capa transparente na frente do olho) e do cristalino, os raios são focados sobre a retina em pequenas regiões em $R, S$ e $T$ (com outros pontos em $V Y$ projetando para todos os pontos entre um e outro).

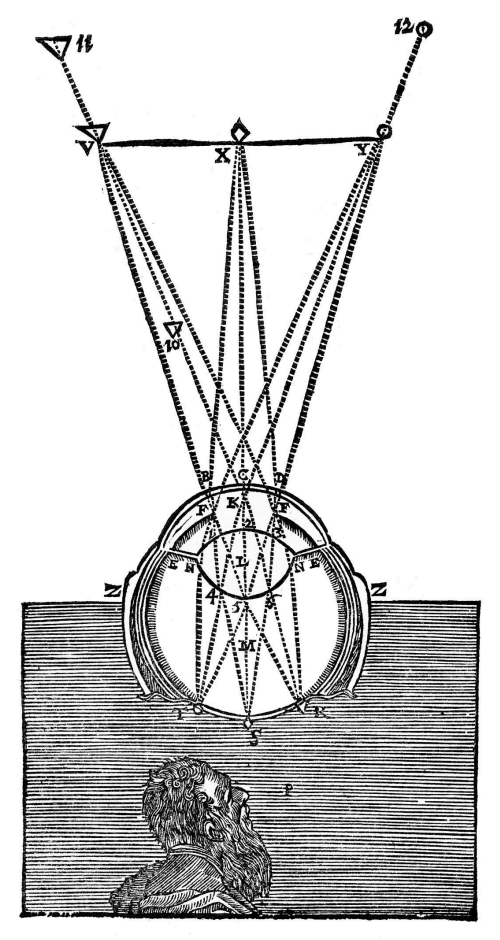

Figura 7. Reflexão de luz a partir de pontos externos $V, X, Y$ para dentro do olho. A refração adequada dos raios de luz foca a luz nos pontos $R, S, T$. Originalmente publicada em Descartes (1637, p.36). Reproduzida de Descartes (1692, p.58).

Até aqui, temos o caminho físico da luz até a retina. Uma suposição natural, feita Principia 21(2): 167-188 (2017). 
por Descartes e Kepler e geralmente afirmada por teóricos subsequentes, é a de que vemos pontos do objeto na direção em que eles estão, projetando-se para fora do estímulo da retina (Hershenson 1999, pp.12-15). Portanto, deveríamos experienciar o ponto $Y$ como na direção projetada a partir de $T$ e os pontos $V$ e $X$ em suas próprias linhas de projeção. De acordo com a suposição amplamente sustentada de que vemos em linhas retas direcionadas às regiões iluminadas que enviam luz para a retina, aceitamos prontamente que é assim que o olho funciona. Se considerarmos, então, que essas direções visuais formam os ossos de nossa experiência no mundo tridimensional, podemos usar essa geometria de raios para entender a percepção de tamanho e forma. Assim, aceitando que vemos os diversos pontos do objeto $V Y$ na direção em que eles estão, podemos ver a forma e a distância de $V Y$ ao perceber as distâncias até esses pontos.

Agora farei uma pergunta que, de tão básica, vai parecer ridícula. Por que deveríamos ver os pontos $V, X, Y$ nas direções em que eles estão? Isso é o mesmo que perguntar por que os estímulos retinais em $R, S, T$ deveriam produzir a experiência de uma pequena região de luz localizada nas direções que vão para $V, X, Y$. Não pode ser simplesmente uma questão de direção da luz. Se fosse apenas isso, por que não experienciaríamos todas as direções que a luz segue ao se aproximar de cada ponto retinal, como representado no feixe de raios convergindo no ponto $R$, no ponto $S$ e no ponto $T$ ? Nesse caso, poderíamos fazer uma projeção de volta a cada ponto ao longo de um cone de raios. Mas não fazemos. Se, no entanto, a direção física real da luz incidente não é suficiente para predizer a direção visual (ao projetar de volta), estamos livres para imaginar diversas relações entre o estímulo de pontos retinais e a direção experienciada. Então, por que não fazer a projeção de outras maneiras (Fig. 8)?

Claramente, a nossa intuição é que as direções fenomênicas potenciais para a estimulação de $R$ como mostrado na Figura 8 não produziriam um bom resultado. Para o bom funcionamento da visão, devemos ver a luz na direção da qual ela vem ao traçar uma única linha através do centro do olho (ou do centro de foco), tal como as linhas de $R$ até $V$, de $S$ até $X$ e de $T$ até $Y$. Contudo, note que isso já é uma transformação. A luz que atinge a retina não traz consigo a informação sobre a direção de onde ela veio. É apenas por causa da peculiar psicofisiologia de nosso sistema visual que o olho tem a experiência de um ponto luminoso como estando na direção (central) da qual a luz veio. O ponto de luz na retina não é uma cópia da direção, mas meramente um resultado físico da luz vindo de certa direção. Dessa forma, temos aqui uma transformação da luz estimulando a retina para a experiência de uma direção visual. De acordo com CT, temos uma construção.

Olhando ainda mais de perto, vemos que essa construção é mais complicada do que o anunciado. Na verdade, a óptica do olho muda para a visão em curta e em longa distância. Isso quer dizer que os caminhos tomados pela luz no olho também mudam. 


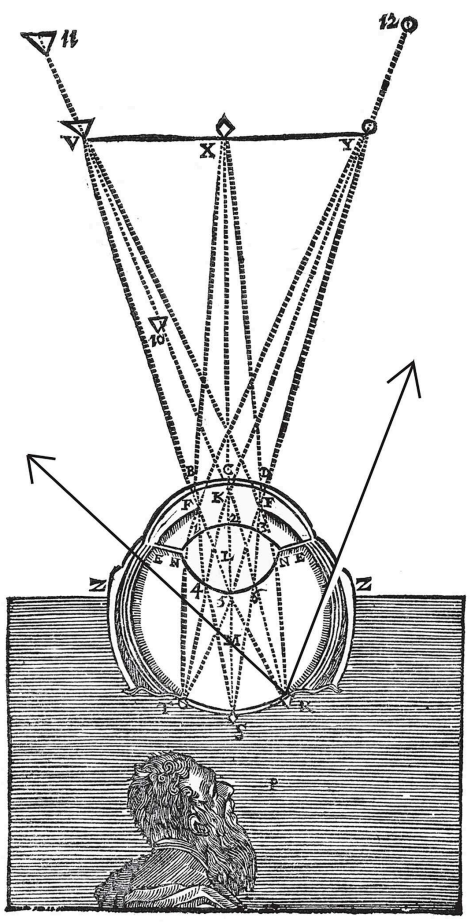

Figura 8. Não há razão lógica (ou puramente física) pela qual a estimulação em $R$ não deveria resultar em uma experiência localização na direção da flecha à direita, ou da flecha à esquerda, ou em qualquer outra direção.

Se assumirmos que a direção visual a partir da retina é preservada, a direção visual experienciada tem primeiro uma e depois outra relação com um caminho central de luz no olho. O cristalino precisa se acomodar, mudar seu formato, para produzir uma imagem em foco para objetos em distâncias diferentes (digamos, $1 \mathrm{~m}$ e $2 \mathrm{~m}$ ). A Figura 9 mostra as distâncias focais no olho correspondentes às duas flechas à esquerda. $B_{1}$ é a distância focal para a flecha de longa distância, e $B_{0}$ para a flecha de distância mais curta. De modo a ver ambas com o mesmo ângulo, como se espera ao assumir que a imagem retinal da flecha, FG, é a mesma nos dois casos, deve haver construções diferentes da direção visual em relação ao caminho físico central feito pela luz dentro do olho como acomodado para as flechas de curta e de longa distância.

Porém as coisas ficam piores, pelo menos para quem quer negar a construção. Até aqui, considerei a direção visual para apenas um olho. Só que a visão humana normalmente envolve dois olhos, como na figura 10. Os dois olhos são direcionados a um ponto focal (ponto de fixação $F$ ). Esse ponto focal pode estar mais perto ou mais longe e os olhos se ajustarão à distância. Mas como experienciamos o ponto 


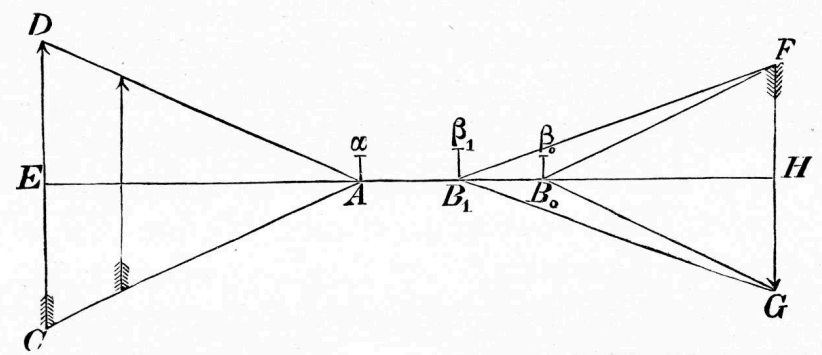

Figura 9. Diferentes distâncias focais quando o olho se acomoda para perto $\left(B_{0}\right)$ ou para longe $\left(B_{1}\right)$. Fonte: Helmholtz (1867, p.584).

focal? Temos a experiência de vê-lo ao longo de duas direções, uma para cada olho (linhas $F_{L} F$ e $F_{R} F$ )? Isso pode acontecer se fecharmos primeiro um olho e depois o outro enquanto fazemos foco em um único dedo à distância de um braço. E com os dois olhos abertos, como é geralmente o caso? Assim vemos o objeto à nossa frente, em certa direção a partir do centro do rosto, ou a partir de um ponto entre os dois olhos, como ilustrado na Figura 10 (direção $d_{F}$ ). Este aspecto da visão humana é chamado "visão ciclópica", em homenagem aos antigos ciclopes (Julesz 1971). Mas o olho ciclópico da visão humana normal é um olho virtual, ou construído. Usando dois olhos, nós vemos coisas em uma única direção a partir do centro da face (direções $d_{A}$, $d_{F}$ e $d_{B}$ ), e não em duas direções, uma para cada olho (veja Hershenson 1999, pp.1723). Mais uma vez, trata-se de construção por transformação. Esse tipo de construção está em toda parte na visão humana. O argumento para essa transformação não depende de informação empobrecida, ou de uma atitude especial, ou de meus pontos fenomênicos a respeito do espaço visual contraído. De acordo com esse argumento, a visão humana é construída até em seus próprios ossos. Isso é o que eu tinha prometido mostrar. $^{5}$

\section{Referências}

Blumenfeld, W. 1913. Untersuchungen über die scheinbare Grösse im Sehraume. Zeitschrift für Psychologie und Physiologie der Sinnesorgane 65: 241-404.

Daoust, L. 2017. Seeing Things As We Do: Ecological Psychology and the Normativity of Visual Perception. Ph.D. Dissertation. University of Pennsylvania.

Descartes, R. 1637[1965]. La Dioptrique. Maire. Trans: Discourse on Method, Optics, Geometry, and Meteorology, trans. Paul J. Olscamp. Bobbs-Merrill, 1965.

_. 1664[1972]. L'Homme. Angot. Trans.: Treatise of Man, trans. Thomas S. Hall. Harvard University Press, 1972.

—. 1692. Specimina Philosophiae: seu Dissertatio de Methodo, Dioptrice, et Meteora. Knoch.

Principia 21(2): 167-188 (2017). 


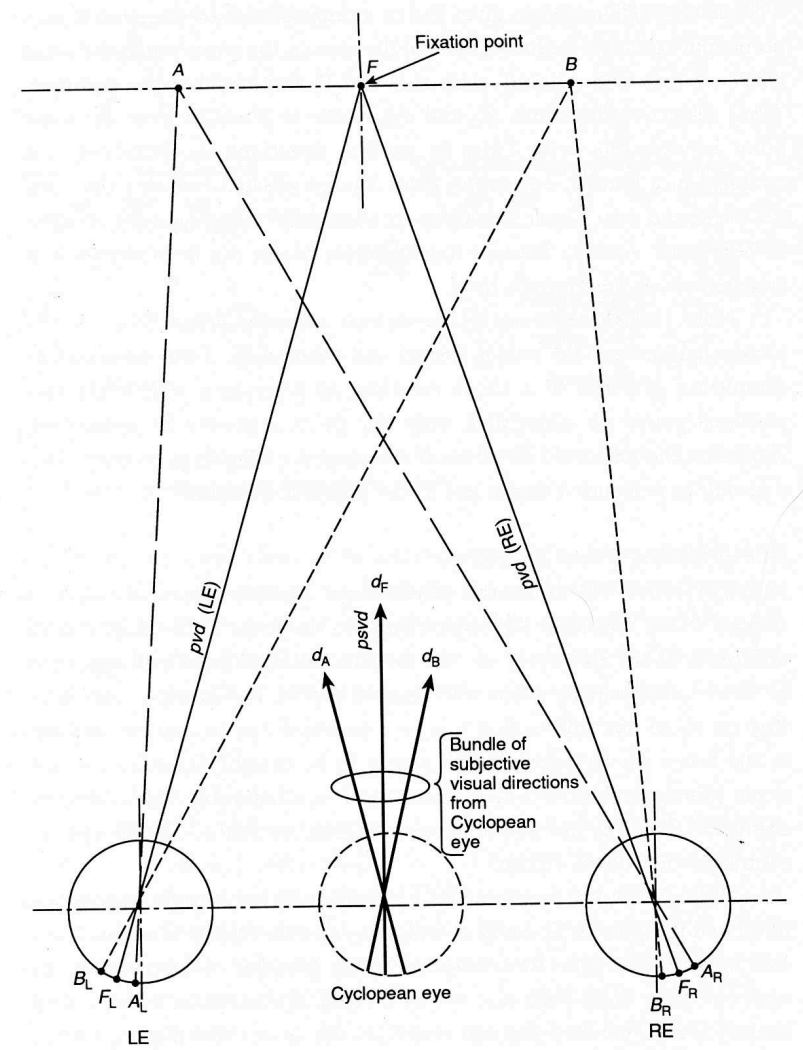

Figura 10. Visão binocular, mostrando pontos no campo de visão como projetados em olhos reais $L E$ e $R E$. As direções visuais fenomênicas ou percebidas procedem do olho Ciclópico (virtual), localizado entre os dois olhos reais. Fonte: Hershenson (1999, p.22).

Duffy, C. J. 2004. The cortical analysis of optic flow. In: L. M. Chalupa; J. S. Werner (eds.) The Visual Neurosciences, vol 2, pp.1260-83. The MIT Press.

Epstein, W. 1994. "Why do things look as they do?": What Koffka might have said to Gibson, Marr, and Rock. In: S. Poggi (ed.) Gestalt Psychology: its Origins, Foundations and Influence, pp.175-89. Olschki.

Gibson, J. J. 1950. The Perception of the Visual World. Houghton Mifflin.

—. 1966. The Senses Considered as Perceptual Systems. Houghton Mifflin. 1979. The Ecological Approach to Visual Perception. Houghton Mifflin.

Goodman, N. 1978. Ways of Worldmaking. Hackett Publishing.

Hatfield, G. 1990. Gibsonian representations and connectionist symbol-processing: Prospects for unification. Psychological Research 52: 243-52.

. 2003. Representation and constraints: The inverse problem and the structure of visual space. Acta Psychologica 114: 355-78.

. 2012. Phenomenal and cognitive factors in spatial perception. In: G. Hatfield; S. Allred (eds.) Visual Experience, pp.35-62. Oxford University Press.

Principia 21(2): 167-188 (2017). 
2016. Perceiving as having subjectively conditioned appearances. Philosophical Topics 44(2): 149-78.

Helmholtz, H. von. 1867. Handbuch der physiologischen Optik. Voss.

Hershenson, M. 1999. Visual Space Perception. The MIT Press.

Hillebrand, F. 1902. Theorie der scheinbaren Grösse beim binokularen Sehen. Denkschrift der Kaiserlichen Akademie der Wissenschaften Wien, Mathematisch-Naturwissenschaftliche Classe 72: 255-307.

Hoffman, D. D. 1998. Visual Intelligence: How We Create What We See. W. W. Norton.

Julesz, B. 1971. Foundations of Cyclopean Perception. University of Chicago Press.

Koffka, K. 1935. Principles of Gestalt Psychology. Harcourt, Brace and Company.

Köhler, W. 1947. Gestalt Psychology: An Introduction to New Concepts in Modern Psychology. Liveright.

Lindberg, D. C. 1976. Theories of Vision from al-Kindi to Kepler. University of Chicago Press.

Neisser, U.; Libby, L. K. 2000. Remembering life experiences. In: E. Tulving; F. I. M. Craik (eds.) The Oxford Handbook of Memory, pp.315-32. Oxford University Press.

Norman, J. 2001. Two visual systems and two theories of perception: An attempt to reconcile the constructivist and ecological approaches. Behavioral and Brain Sciences 25(1): 73-96.

Rock, I. 1975. Introduction to Perception. Macmillan.

. 1982. Inference in perception. In: P. D. Asquith; T. Nickles (eds.) PSA: Proceedings of the Biennial Meeting of the Philosophy of Science Association, Volume Two: Symposia and Invited Papers, pp.525-40. Philosophy of Science Association.

- 1983. The Logic of Perception. The MIT Press.

Slomann, A. 1968. Perception of size: Some remarks on size as a primary quality and "size constancy". Inquiry 11: 101-13.

Palmer, S. E. 1999. Vision Science: Photons to Phenomenology. The MIT Press.

van de Grind, W. A. 1988. The possible structure and role of neuronal smart mechanisms in vision. Cognitive Systems 2(2): 163-80.

Wagner, M. 2006. Geometries of Visual Space. Erlbaum.

Warren, W. H. 2008. Optic flow. In: A. I. Basbaum; A. Kaneko; G. M. Shepherd; G. Westheimer (eds.) The Senses: A Comprehensive Reference, vol 2, Vision II (ed.) Thomas D. Albright; Richard Masland, pp.219-30. Academic Press.

\section{Notas}

${ }^{1}$ Em inglês, PDE (phenomenal deviation from physical environment). N.T.

${ }^{2} \mathrm{Em}$ inglês, CT (construction as transformation). N.T.

${ }^{3} \mathrm{Em}$ inglês, AA (aspect for action). N.T.

${ }^{4}$ Em inglês, size-distance invariance hypotesis, SDIH. N.T.

${ }^{5}$ Traduzido por Ivan Ferreira da Cunha e Renato Cesar Cani

Principia 21(2): 167-188 (2017). 